\title{
Meaningful objects and consumption
}

Link to publication record in Manchester Research Explorer

\section{Citation for published version (APA):}

Woodward, S. (2018). Meaningful objects and consumption. In Oxford Handbook of Consumption Oxford University Press.

\section{Published in:}

Oxford Handbook of Consumption

\section{Citing this paper}

Please note that where the full-text provided on Manchester Research Explorer is the Author Accepted Manuscript or Proof version this may differ from the final Published version. If citing, it is advised that you check and use the publisher's definitive version.

\section{General rights}

Copyright and moral rights for the publications made accessible in the Research Explorer are retained by the authors and/or other copyright owners and it is a condition of accessing publications that users recognise and abide by the legal requirements associated with these rights.

\section{Takedown policy}

If you believe that this document breaches copyright please refer to the University of Manchester's Takedown Procedures [http://man.ac.uk/04Y6Bo] or contact uml.scholarlycommunications@manchester.ac.uk providing relevant details, so we can investigate your claim.

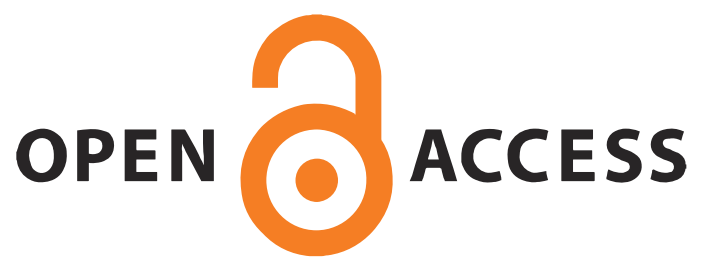




\title{
Meaningful Objects and Consumption
}

Sophie Woodward

\begin{abstract}
:
This chapter explores the ways in which practices of consumption are processes of making social and personal meanings. Drawing upon theories of material culture it highlights that these meanings arise from the co-agency of people and things. Rather than dismissing semiotic approaches as failing to attend to the materiality of goods, it draws from semiotic approaches (Keane, 2005) which allow for an understanding of the material potential of goods as well as an understanding of the interrelationships of objects. This is developed through assemblage theories (Bennett, 2009) to suggest that meaningful goods need to be seen in relationship to objects that have implicit meanings as well as meaningless items such as everyday clutter.
\end{abstract}

Keywords: material culture, appropriation, consumption, methodology, dormant things, collections, assemblages, semiotics, meaningful objects, clutter. 
Consumption is understood here as a set of material practices that take place within the specific context of mass produced goods (variably termed the 'consumer society', see Lury, 2011). The practices that constitute consumption include the acquisition, use, appropriation, display, storage and disposal of objects. Rather than being a separate sphere of activities and goods, consumption is thus an embedded part of everyday life as the wearing of clothes, the eating of food, the organizing of $\mathrm{CD}$ collections are the medium through which we organize our social worlds, relationships to others and develop a sense of self-identity. The point of departure for much of the literature on consumption and material culture has been the challenge of how mass-produced and potentially alienable goods can be utilized by people to develop personal and social meanings (from Miller, 1987). The processes through which things are given meaning are multiple: goods may come with existing connotations through production and advertising but these are shifted and renegotiated or made irrelevant through what people do with them (personalizing, using, displaying), how they talk about them (Woodward, I., 2001, Rowsell, 2011) and how objects move through different contexts (Kopytoff, 1986). At the heart of these processes are the objects themselves as, through their particular material propensities, they enable and limit the kinds of personal and cultural meanings produced. Through sensuous practical engagements with things (Dant, 2010) they become part of our personal and social worlds, as they extend (and limit) the capabilities of our bodies and how they move. There is no static 'meaningful object' but rather through different relationships with people, between people, between different objects, and within particular contexts these meanings emerge, are reinforced and may change.

An emphasis upon how consumers are active in producing meanings is in part a response to the Marxist inspired approaches which looked at how advertising and mass production alienated people from the products of their labor as well as imparted 'false values' in goods. A material culture perspective explores how the active process of consumption arises 
from both the agency of people and the agency of things (see Gell, 1998), as people have intentions and desires in relationship to objects which have particular propensities and material possibilities. The meanings of things emerge from the co-agency of people and things. This chapter will explore how objects can be understood as meaningful within the context of consumption through the approach of objectification and its application developed by Miller (1987), a semiotic approach developed by Keane (2005) which is grounded in the material possibilities of objects as signs and assemblage theory (Bennett, 2009). The chapter will explore how the practices of consumption give objects meaning and how, in this process, objects give meaning to consumption practices. By grounding this discussion in an understanding of how people interact with material objects, the chapter will end by proposing that a focus upon 'meaningful objects' can be limiting. The ordinary, forgotten about objects of consumption may not be immediately evocative, cherished or understood by people themselves as 'meaningful', they are none the less significant and have meanings for the academic study of consumption. Meaningful objects need to be understood in relationship to objects which acquire meaning through daily practices as well as seemingly 'meaningless objects' exemplified by domestic clutter. The chapter concludes by suggesting that an approach that explores material relationalities is most productive in understanding the shifting relationships between objects and meanings.

\section{Defining consumption and material culture}

This section will start by defining consumption as a meaning making activity drawing from anthropological work in particular which allows us to understand the processes through which meanings are created. I will then consider how, as objects are central to this process, we can understand the material agency and potentials of these objects. A good starting point for defining consumption comes from Douglas and Isherwood's seminal discussion of 
consumption and the 'world of goods' (1979) where consumption is seen as a meaning making process. Slater extends this to see it as part of the process of 'making social sense' (Slater, 1997: 172). Through giving meaning to objects through consumption (Woodward, I., 2007), these objects are giving meaning to our lives. As we use, store, buy, cherish, dispose objects, these objects of consumption help to co-create our social lives; as these objects move through different domains and regimes of values (Appadurai, 1986), tracing the particular object's social live or biography (Kopytoff 1986) allows us to see context specific meanings emerging. Whilst Koyptoff's approach has been criticized for failing to attend sufficiently to the materiality of things in permitting different cultural meanings and relationships, it is useful in highlighting both how the meanings of things are not fixed but change depending upon cultural contexts. An aspect of the commodity's biography that Kopytoff outlines is the movement between the commoditized state (where things are reduced to their exchange value) and the individualized state, wherein objects are singularized through personal meanings or marked with cultural significances. Consumption that occurs in a context of mass produced goods is a process that involves encountering and interacting with goods that we did not make but that capitalist structures of production and advertising produce and attempt to impart meanings onto them. Consumption involves use of things in production (so consumption is not just in opposition to production) but also as processes of acquisition, use, storing, display, disuse, repair and disposal.

Although coming from very different perspectives to Kopytoff, this interplay between an object whose meanings are defined by its commodity status and an object whose meanings are rooted in people's social worlds is at the heart of many theories of consumption. For instance, Simmel (1950) discusses this interplay in terms of the relationship between objective and subjective culture; Miller's theory of objectification (1987) explores it in terms of the movement between alienable and inalienable goods. In all of these different variants, objects 
can shift between being alienated, commoditized or subsumed within objective culture and being a personalized, inalienable part of subjective culture. Consumption thus understood is a struggle to make objects a meaningful part of our personal and social relations and is a way of negating the potentially negative and alienating facets of contemporary society (Miller, 1997).

This struggle to make objects meaningful is at the heart of Miller's theory of objectification (1987) and is worth visiting in more depth here not only due to its significant influence upon the field of material culture and consumption studies but also as it allows a theoretical understanding of how people can, in his terms, 'appropriate' the products of mass consumption. This is central to the development of the self as well as forming the foundations for the constitution of social relations. In Miller's sense, consumption is a process that begins with products that we have not created, this process is a dynamic relationship between subject and object at its heart in a process of 'becoming' (1987: 33). Drawing from Hegel, Miller's theory of objectification positions the objects of mass consumption as a central part of the development of the self. It is a dual process wherein the subject externalizes itself (such as when we see ourselves in material objects), which is then re-appropriated as the self is subsequently changed. A dynamic relationship between a person and the objects of mass consumption occurs, where the alienable goods are a medium through which the self is developed and therein the objects become inalienable. An intrinsic part of this dynamic is that the subject is continually externalized and then appropriated as part of the progressive development of the subject. 'Consumption as work may be defined as that which translates the object from an alienable to an inalienable condition; that is, from being a symbol of estrangement and price value to being an artefact invested with particular inseparable connotations' (Miller, 1987: 190). Miller uses the word 'work' here to mean what people and groups do with objects, relating to time of possession, context of presentation, where objects are placed, how they are used and so on. And so, although Miller's theory is useful in 
understanding the ways in which significant relationships between individuals and objects can develop, this always occurs within wider cultural norms and expectations over what you do with certain objects in particular contexts. The creation of inalienable culture is central to how social relations can be constituted.

Douglas and Isherwood (1979) suggested that the main meaning of goods is to make 'visible and stable the categories of culture' (1979: 59). The ordering, use and positioning of goods is also the mapping of our social worlds, the making visible of hierarchies and power relations. Consumption of objects is a medium for performing and affirming social relations; as an embedded cultural practice, people are constructing meaning though objects as discriminating between objects is also drawing distinctions between people and a way of marking aspects of the self. Consumption is a process of cultural reproduction (Slater, 1997) as, for example, we eat particular foods using particular conventions and competences which reproduces culturally specific ways of consumption as well as our position within that culture. One of the most influential discussions of how social classifications are made visible through consumption can be found in Bourdieu (1984), as well as the prolific work inspired by his development of a theory of practice where taste is socially structured and how the social order is reproduced. Objects are markers of cultural value and a visible marker of difference as the distinctions between things are also the ways in which social distinctions and inequalities are reproduced.

Shared meanings are reiterated when we consume, and yet this is also a moment for potential subversion or changes. These shared meanings exist at a number of levels, that of a particular national culture, specific groups within this and even more specifically familial traditions and rituals around consumption practices. Meaningful goods are not however in opposition to goods that are either 'useful' or understood as goods that are needed (Slater, 
1997). As there are still cultural codes around, for example, what food is considered edible and how it is consumed even if it is needed. Function or need cannot be separated out as an aspect of consuming objects as these are always culturally meaningful.

Within the approaches discussed so far, objects are in integral part of consumption, and so, it is important to think concretely about how we understand objects in the process of meaning making, as they are not just inert vessels into which we can pour personal and cultural meanings, but rather they enable particular interactions, meanings and relationships. It is not just people who have agency but rather as objects bring about effects they too can be understood to be co-agentic (Gell, 1998). The material ways in which objects do this have been variably understood as having 'affordances' (from Gibson, 1979) or propensities as material attributes like colour, texture, weight, design all impact upon how things might lend themselves to different cultural meanings. And so, a grandmother's old ring can be passed down as it becomes a lasting connection between generations, whereas an old perfume bottle that contains the last drops of perfume is a more transient yet multisensory way through which a person is remembered. Objects can be unpredictable as we may like an object because it is red, but this attribute is always 'bundled' (Keane, 2005) with other attributes like shininess, lightness as it is part of a particular object.

Objects also have 'relational capacities' (Lury, 2011: 57), in terms of the relationships to people they open up, allow and limit and between different objects. The objects we interact with exist in relationship to other objects. So, for example, an item of clothing relates to all the other clothing already owned within the wardrobe. These material relationships produce meanings for individual items, as a new smart jacket can render other ones scruffy. Woodward, S., and Greasley (2015) have developed an approach to consumption that situates an understanding of how people relate to different types of material goods (such as clothing or music) within the 'collection' as a whole, such as a CD collection or a wardrobe. The 
collections can be theoretically reframed as 'assemblages' to allow an understanding of the materiality of the collection as a whole, as this connects to the material practices or wearing, listening, storing, displaying or disposing. Drawing from Bennett (2009), assemblages are made up of the relationships between diverse, materially vibrant elements (including for example, clothing, people, dust). Its 'uneven topographies' (Bennett, 2009: 24) mean that different groupings of things can have more power over us at different times, as the collection as a whole shifts in the meanings it has as well as the meanings of individual objects, which impact upon as well as draw from the collection as a whole. The materiality of things centres then upon the properties of things as these change, the relationship between things within specific contexts. People are part of these material relationships as the ways in which on object is used in turn impacts upon how objects relate to each other.

\section{Semiotic approaches and materiality}

Seeing consumption through the theoretical lens of material culture is often a direct critique of semiotic approaches through their failure to attend to the materiality of objects that are central to the processes of meaning making within consumption. Certainly, the dominant ways in which semiotic approaches to consumption have been developed derive from de Saussure's position which sees components of culture as if they were elements of language that can be interpreted like a text. As a consequence, often semiotic accounts are positioned before a discussion of the anthropological and material culture accounts, as the latter critiques the former. However, whilst these critiques matter, I have chosen to place semiotics in this section to both build upon the ideas of relationality already discussed and also to explore the potentials for a semiotic approach that is sensitive to materiality. I will outline this approach to an understanding of how objects become meaningful and then explore an alternative semiotic approach which places the materiality of things at the heart of their ability to signify. One of

Formatted: Right: $0.63 \mathrm{~cm}$ 
the most prominent developments of semiotic approaches to consumption is Baudrillard's development of the theory of signification wherein object-signs are organised in a system from which individual objects derive their meaning. Objects are signs that refer to something other than themselves, such as identity or status. In Baudrillard's formulation, objects have symbolic value in relationship to each other; as sign-value is always relational the differences between object-signs is where their meanings arise. Consumption not as an autonomous arena but where cultural divisions are played out as, for example, objects may be symbolic markers of class status and prestige. Baudrillard's definition of consumption is thus that it is 'an activity consisting of the systematic manipulation of signs' (1996: 200).

These perspectives centre up on how things acquire meanings and the particular strengths of these approaches include how it considers the ways in which meaning is produced relationally. However, it has rightly been criticised for failing to attend to the ways in which meanings may be created through social practices that consumers engage with and that emerge through a material interaction between person and object. What may appear to be the natural qualities of things are the product of mythologies (Barthes, 1967) where what is signified may have no inherent connection to the object itself. Objects cannot be understood as a text, and their materiality impacts upon how they are able to produce meanings, as moreover, consumers may read objects in multiple ways through their situated knowledges and competences (Campbell, 1997). Even the understanding of how meanings are imparted on objects is problematic as meaning and cultural systems are seen to precede objects which then become passive vessels in which meaning is placed. As part of this an objects function is seen as separate to the meanings that are imparted on it. However, an objects function cannot be separated from the meanings it may have, as these are in Keane's term 'bundled' together.

However, rather than casting semiotic perspectives aside, Keane (2005) has explored the possibility of a semiotic approach which interrogates the materiality of the objects as signs. 
Objects are no longer a passive medium to communicate something else but, drawing from Pierce, signs are located in a 'material world of consequences' (2005: 186). Keane identifies 3 possible relationships among signs, interpretations and objects: resemblance (iconicity), connection (indexicality) or rule (symbolism). He focuses in particular upon iconicity, which points to the similarities between the form of the sign and its meaning, rather than the relationship between an object and what it signifies being arbitrary. There is a connection between the material form and what it signifies as objects have material potentialities as signs. Keane suggests that the ways in which objects signify is complex and often unpredictable. A material quality such as 'lightness' can be abstracted as we understand what this quality is, and yet when it is embodied in a particular object, it cannot be separated from the other material qualities it is bundled with, so, for example, a red shoe is also a particular sheen and weight. These other attributes have effects on the objects social life and the meanings it is able to produce. So too the social values that an object may signify are embodied in particular objects which bring together a number of attributes and qualities.

Iconicity can be 'open' (Keane, 2005), as the meanings of things and the things people do with them are not determined but open to be interpreted, such as when colonial subjects turned Western shirts upside down and wore them as pants (Keane, 2005). This 'potential' of objects is not just a product of the objects material qualities, as they are part of a semiotic ideology, that is, culturally specific assumptions about what signs are and how they function. In different contexts, this ideology can be more or less restrictive depending upon how the material qualities are read and how. The material qualities may make things possible and inhibit others, and yet they do not determine. Keane suggests then that it is not enough to see what things mean to people as we also need to understand how they are regimented within semiotic ideologies which bring things into relation with each other. These semiotic ideologies are not fixed as they are vulnerable by being materialised in objects, which through the bundling of 
attributes as well as the openness to how things may be used means that what is signified may change.

This dovetails with wider discussions over the relationship between agency and constraint in how objects are used in processes of making and contesting meanings. From a very different perspective, Willis (1990) argues that things are polysemic and there are struggles over meaning as people engage in 'symbolic work' with everything they buy cited (Willis cited in Slater, 1997: 168). As Miller 1987 makes clear, not all consumer objects are equally polysemic, as seen in examples of the built environment such as council flats, there is much less space for customization. Some objects we are more able to subvert and reappropriate (Miller, 1987). The constraints come from the objects themselves, social norms, existing power relations and the social relations within which consumption occurs. Constraint in how people consume appears to be in opposition to freedom to create meanings, but these contradictory tendencies co-exist within contemporary consumption practices. As they are not verbal ideological control as well as the opposing tendency of dissent, objects lend themselves to the articulation of both (Miller, 1987).

\section{Meaningful objects and objects that have meaning}

This chapter has so far engaged with the approaches that help to best understand how objects have meanings. However, there is a distinction between objects having meaning and being a 'meaningful object'. The term 'meaningful object' suggests that an object has personal and cultural meanings of which people are aware and are able to articulate. This is not the same as an object being analysed by academics as having meaning, (Woodward, I., 2001, has noted that there is a potential discrepancy between how people see objects themselves and how the analyst might). Woodward goes on to suggest that once we listen to what people say then multiple interpretations/meanings/practices come into play. Whilst it is certainly true that 
getting people's accounts helps us to understand meanings they have for people, and also process of talking about things is also process of giving them meaning (Hurdley, 2006), this process of getting peoples stories can also be one of academics turning it into a 'meaningful object'. For example, when I piloted my Dormant Things project - which looks at objects within the home that are currently not being used - on my own home, I used the example of a table we have in the kitchen. It belonged to my husband's grandmother and was passed down when she downsized to a flat; for the pilot I interviewed my husband about where the table was from, when he remembered his grandmother using it. I was left with rich narratives of the table as it came to appear as an object laden with personal and relational meanings. And yet as I reflected upon this, it bore little relationship to the actual practices of the table in our lives. It was a functional kitchen table, usually covered by a table cloth and mass of household clutter. It is not an object that is ever reflected upon, nor is it one that I was even aware of the history of. And so, through the interview I turned the table that was part of everyday domestic life and routines into a 'meaningful object'. When we have these narratives it is very difficult not to place these at the heart of out interpretation.

Meaningful objects are also a product of methods which prioritise words to understand objects which often, by their material nature are not verbalised. This is not to suggest that they cannot be verbalised in ways through we can attune ourselves to the material (see Woodward, S., 2015b), but does raises issues about how we understand the particularities of material culture if material culture is something we come to know through material practices. Dant (2010), citing the example of car repair, suggests that we understand objects by engaging with them through the senses. So, for example, how mechanics interact with cars is through sensual knowledge, not just sight but also touch. In order to understand and explore these material interactions, Dant employs visual methods (such as video stills) as well as wider observations. For Miller (1987), albeit from a very different theoretical perspective, we experience objects 
through culturally specific contexts, as the material properties of things need to be understood in particular contexts as 'the physicality of the object lends itself to the work of praxis - that is, cultural construction through action rather than just conceptualization' (Miller, 1987: 129) or symbolism. Context specific understanding of how people interact with objects is explored through ethnographic observations (Miller 1997). Focusing upon objects as 'meaningful' may now allow these elements of non-verbalised practice which may often be routine, material practices (Reckwitz, 2002), which are at the heart of consumption (Warde, 2015), where objects are understood in terms of their place in collective meaning structures to be interpreted, rather than as agentic.

\section{Meaningless objects}

Understanding of material culture and consumption needs to incorporate meaningful objects as objects which have significant subjective investment in them, yet also things which matter through routine interactions with them. An interview may be an occasion for reflecting as participants become aware of the object and the central role it may have in their daily lives. These objects matter in relationship to the processes and practices through which they come to have meaning in the organisation of daily life and enacting personal and social relationships. There is a distinction then between meaningful objects which can be understood as through which have a strong personal attachment to and understanding of their meanings and objects which acquire meaning though everyday practices and interactions even if participants are less conscious of this. Objects may have meaning to participants that operates at the level of the unconscious (Miller, 1987), and such objects are often those of most interest (and having the most meaning for) academics interested in the routine material practices that constitute consumption. In addition to this are objects which might be understood as 'meaningless' by 
participants and I will close the article with highlighting how these can widen out the remit of understanding the relationships between consumption, objects and meanings.

One framework for thinking about meaningful and meaningless goods is through the opposing and yet coexisting relationships that Miller (from Hegel) identifies between alienable and inalienable (Miller, 1987) objects. As the process of self-alienation is an inevitable part of the process of objectification that the subject tries to overcome, this speaks to the wider coexistence of the negative and positive elements of consumer culture more widely and the contradictions between objects which become a part of our self-identity and those we encounter as alien goods. Simmel (1950) suggests that in a context of the rise in the quantity of consumer goods then we are less able to recognise ourselves in the expanded objective culture or that we are overextended in more superficial relations with things. Thus different contradictory relationships between people and things co-exist within contemporary consumer societies. In order to understand people's relationship with everyday objects it therefore matters to position meaningful goods in relationship to those with less or no subjective investment in. This is not just an intellectual conceit if we consider the range of objects within people's homes; within my current research into dormant things in the home I have looked at the all of the things that people keep but are not currently using (see Woodward, S., 2015 for an outline). These objects include cherished items that remind the owner of a time in their life (and thus former self) or of someone else (and thus it externalises relationship to other people) as well as objects that people do not even know the provenance or those which are understood as meaningless clutter. These could be understood within the framework of both Miller and Simmel (1950) as being both the inalienable and alienable, those which people have a significant relationship with and those which they do not. However, not only is clutter instructive in helping us to understand how everyday life in the home is organised, how gender relations are enacted amongst other things, reducing it to things which people have failed to 'appropriate' is insufficient.

Formatted: Right: $0.63 \mathrm{~cm}$ 
The second framework that is useful here is as approach that considers 'the lives of things'; for instance within the dormant things fieldwork, there were many examples of people who kept objects simply because they have had it in their possession for a long time. Because the object has resided in their homes for a lengthy period of time, people feel they are unable to get rid of it. This dovetails with Gregson's ethnographic research (2007) where she explored how things come to be discarded from the home in the context of wider domestic practices with things such as sorting, and tidying. She highlighted both endurance and transience as being key temporalities in relationship to objects within the home, which may be more important than whether objects are meaningful. So for example, one of her participants has a microwave they have kept for 14 years, which may have been there for a long time, but not through any capacity for people to narrative themselves with. Some objects may not be heavily invested with meaning, even if they remain in the home for a long period of time after the object has ceased its useful life.

The third framework is one that draws from previous discussions of semiotics, and assemblage theories to develop an understanding of the relationship between things, which would include the relationship between meaningful objects and clutter as this shifts or is sedimented through everyday practices. One of the strengths of semiotic approaches to consumption is the emphases upon the relations between object signs in the production of meanings. A more useful approach to thinking about the relations between material things and the meanings they might have or the uses to which things are put can be found within assemblage theory. As discussed earlier, Jane Bennett's formulation of assemblage theory (2009) where assemblages consist of multiple material components which are vibrant, and thus relationships between these elements change. When applied to everyday assemblages of objects within the home (see Woodward, S., and Greasley, 2015), we can use this approach to understand how collections of objects such as a CD collection, or a drawer of clutter has a

Formatted: Right: $0.63 \mathrm{~cm}$ 
power over us and helps create the meanings of individual items. On object placed in the clutter drawer may be rendered meaningless, but on a sort out, may be reframed as cherished and this meaningful and put in a memory box in an attic. Where things are placed, and how they relate to other objects helps create the meanings they have. These relations are not just between 'objects' but materially diverse elements, such as dust, and so an object covered in dust may create its meanings as old, or unwanted. This thinking can be extended even further is we draw from Keane (2005) and his suggestion that we need to think about the relationship between material qualities within an object to see how meanings are created. These material relationalities operate on many different levels: between objects, between objects and people, objects and spaces and between material attributes. This approach allows us to think about how things change meaning and how meanings are acquired.

\section{Conclusion}

A key feature within the proliferation of literature on consumption since the late 1980s has been to explore the ways in which consumption is a meaningful process. Some of these have been explicitly engaging with meaning making from a perspective which critiques semiotics approaches where the meanings of goods are imparted through the wider cultural system of signification instead exploring ways in which everyday practices can help create personal, cultural and relational meaning for people. In particular material culture approaches attest to the agency of things and the capacities of objects to allow people in particular contexts with social norms to create meanings. This chapter has suggested that whilst these approaches to understand how objects may become meaningful are instructive, it is important to see meaningful objects in relationship to objects that have meaning through everyday practices but may not be explicitly reflected upon by participants, and meaningless objects. Thinking about everyday objects in these three categories is a device to widen out our understandings of 
everyday consumption practices and indeed reflect upon the methodologies through which we think about the meanings of things. Whilst the academic may find meaning in all three types of object, it is only meaningful objects that people are consciously aware of their personal and social significance. These categorisations moreover shift as no object is always, for example, a meaningless object as on occasion of a sort out it may be re-categorised as meaningful. Equally objects which are a key part of the organisation of everyday life and relationships may be reflected upon on the occasion of a sort-out, or a reorganisation of the home and in this process become imbued with meanings.

Three frameworks for understanding these three types of objects have been suggested, and these all engage with thinking about the relationships between different kinds of things. Firstly the contradictions between alienable and inalienable goods that are inherent to a mass consumer society were extended to meaningful and meaningless objects and as open to change as objects can shift in their meanings. Secondly, an approach which explored the lives of things through notions of endurance and transience was introduced to suggest that the relative persistence of things in our lives may not just be reduced to the meanings they have. Finally, assemblage theory (in particular Bennett's version 2009) proves a useful approach to think about assemblages of goods within different spaces in the home, whether these are in a clutter drawer, or categorised through material similarity (such as kitchen implements). This framework is one that pays heed to the material capacities of different objects and elements, as these relate to each other, and as materially dynamic as, again, things can shift in meanings. This chapter points towards the need to widen the study of consumption and material culture to incorporate the meaningful and the meaningless within a relational framework in order to understand the vibrancy and diversity of how things acquire, maintain and lose meanings.

Formatted: Right: $0.63 \mathrm{~cm}$ 


\section{References}

Appadurai, Arjun. (ed) 1986 The Social Life of things. Cambridge: Cambridge University Press.

Arnould, Eric. and Thompson, Craig. 2005. "Consumer Culture Theory (CCT): Twenty Years of Research." Journal of Consumer Research 31, no. 4 (2005): 868-82. doi: $10.1086 / 426626$

Barthes, Roland. 1967. The Fashion System. New York: Hill and Wang.

Baudrillard, Jean. 1996. The System of Objects. London: Verso.

Bennett Jane (2009) Vibrant matter: a political ecology of things. Durham: Duke

Bourdieu, Pierre. 1984. Distinction: a social critique of the judgment of taste. London: Routledge.

Campbell, Colin. 1997 'When the meaning is not a message; a critique of the consumption as communication thesis' pp 340-351 in Nava, M, Black, A, MacRory, I and Richards, B. (eds) Buy this book: studies in advertising and consumption. London: Routledge.

Dant, Tim. 2010 The work of repair: gesture, emotion and sensual knowledge in: Sociological Research Online, Vol. 15, No. (3), 7, 31.08.2009, p. n/a

Douglas, Mary and Isherwood, Baron. 1979. The World of Goods. London: Allen Lane.

Gell Alfred (1998) Art and Agency. Oxford: Clarenden Press.

Gibson, James. (1979) The Ecological Approach to Visual Perception. Boston: Houghton Mifflin.

Gregson, Nicky. 2007. Living with Things: Ridding, Accommodation, Dwelling. Sean Kingston Publishing.

Hurdley, Rachel. (2006) 'Dismantling Mantelpieces: Narrating Identities and Materialising Culture in the Home', Sociology, 40(4), 717-733.

Formatted: Right: $0.63 \mathrm{~cm}$ 
Keane, Webb. 2005 'Signs are not the Garb of Meaning: on the social analysis of material things’ pp 182-205 in Miller, D (ed) Materiality. Durham: Duke University Press.

Kopytoff, Igor. 1986. 'The cultural biography of things: commoditization as process' pp 64-94 in Appadurai, A. (ed) The Social Life of things. Cambridge: Cambridge University Press.

Lury, Celia. 2011. Consumer Culture ( $2^{\text {nd }}$ Edition). Cambridge: Polity.

Miller, Daniel. 1997. Consumption and its consequences pp 13-65 in Mackay, H. (ed). Consumption and Everyday Life. London: Sage.

Miller, Daniel. 1987. Material Culture and Mass Consumption. Oxford: Blackwell.

Reckwitz Andreas. 2002. The status of the "material" in theories of culture: from "social structure" to "artifacts"'. Journal for the Theory of Social Behaviour 32:2 195-

Rowsell, Jennifer. 2011, Carrying my Family with me: artefacts as emic perspectives' in Qualitative Research June 2011; vol. 11, 3: pp. 331-346

Slater, Don. 1997. Consumer Culture and Modernity. London: Polity.

Simmel, Georg. 1950. The Sociology of George Simmel (ed K. Wulf). Glencoe: The Free Press.

Warde, Alan 2015 The Sociology of Consumption: Its Recent Development in Annual Review of Sociology 2015 41:1, 117-134

Willis, Paul. 1990. Common Culture. Milton Keynes: Open University Press.

Woodward, Ian. 2007. Understanding Material Culture. London: Sage. Not referenced in text?

Woodward, Ian 2001. "Domestic Objects and the Taste Epiphany. A resource for consumption methodology'. Journal of Material Culture, 6 (2): 115-36.

Woodward, Sophie. 2015a The Hidden Lives of Domestic Things: Accumulations in Cupboards, Lofts, and Shelves. In: Casey E., Taylor Y. (eds) Intimacies, Critical Consumption and Diverse Economies. Palgrave Macmillan Studies in Family and Intimate Life. Palgrave Macmillan, London

Formatted: Right: $0.63 \mathrm{~cm}$ 
Woodward, Sophie. 2015b. 'Object interviews, material imaginings and 'unsettling' methods: interdisciplinary approaches to understanding materials and material culture' in Qualitative Research [online first]

Woodward, Sophie and Greasley, Alinka. 2015b. 'Personal collections as material assemblages: A comparison of wardrobes and music collections' in Journal of Consumer Culture [online first, DOI: 10.1177/1469540515611202]

Formatted: Right: $0.63 \mathrm{~cm}$ 